\title{
Exempted Testing of Deep-set Buoy Gear and Concurrent Research Trials on Swordfish, Xiphias gladius, in the Southern California Bight
}

\author{
CHUGEY A. SEPULVEDA and SCOTT A. AALBERS
}

\section{Introduction}

The swordfish, Xiphias gladius, is a highly migratory species that supports vast fisheries around the globe (Ward et al., 2000). In addition to annual migrations that may span thousands of kilometers in a single season, swordfish also exhibit daily vertical movements that transition from surface waters at night to those below the thermocline during the day (3001,000 m; Carey and Robison, 1981; Carey, 1990; Sepulveda et al., 2010; Dewar et al., 2011). Over the past century, swordfish fisheries have evolved to capitalize on this behavior pattern, with most fishing activity occurring at night, within the waters of the upper mixed layer (above the thermocline) (Ward et al., 2000).

Among the gear types currently used to target swordfish in the North Pacific, shallow-set longline has become the most common harvest method followed by drift gillnet and harpoon op-

C. A. Sepulveda and S. A. Aalbers are with the Pfleger Institute of Environmental Research (PIER), Oceanside, CA 92054. Corresponding author is Chugey Sepulveda (chugey@pier.org).

doi: https://doi.org/10.7755/MFR.80.2.2 erations, with the latter two fisheries only occurring in a few select locations (Hanan et al., 1993; Coan et al., 1998; Ward et al., 2000). Although swordfish are more accessible near the surface at night, this time and depth also results in high spatial overlap with nontarget species (Beverly and Robinson, 2004; Gilman et al., 2006; Sepulveda et al., 2014). In particular, shallow-set swordfish fisheries have been routinely scrutinized by conservation groups for their lack of selectivity and high incidence of interaction with species of special conservation concern (i.e., sea turtles, marine mammals, and sea birds; Gilman et al., 2007).

Within the exclusive economic zone off California ( CA EEZ), the primary gear type used to harvest swordfish is the California drift gillnet (DGN), a technique that has received regulatory scrutiny over its lack of selectivity and past history of interactions with species of special concern (i.e., marine mammals and sea turtles; Carretta et al., 2004). Over the past three decades, the DGN fleet has declined to historic lows in participation, landings, and revenue, with recent interactions with protected species threatening further restriction (NOAA, 2001, 2014; Martin et al., 2015; Urbisci et al., 2016).

Historically, options for reducing bycatch in the DGN fishery have primarily focused on gear modifications (i.e., acoustic pingers, extended surface suspenders) and the use of seasonal closures to reduce spatial overlap with sensitive species (i.e., leatherback sea turtles, Dermochelys coriacea; Carretta et al., 2004; Martin et al., 2015; Eguchi et al., 2016). Although effective, these restrictions have severely limited the temporal and geographic scope of the DGN fishery, with most of the fishing activity now consolidated to the U.S. portion of the Southern California Bight (SCB), a body of water that extends from Point Conception (34 $27^{\prime}$ and $120^{\circ} 28^{\prime}$ ) to below the Mexican border and out to $300 \mathrm{~km}$ (Daily et al., 1993). Despite the decline of west coast swordfish operations, local demand continues to exceed domestic production, a scenario that further fuels the U.S. Pacific coast's reliance upon foreign fleet imports for meeting local consumption needs (Rausser et al., 2009).

Given the suppressed state of this swordfish fishery, recent management
ABSTRACT-Research and exempted fishery trials were performed off the U.S. west coast using deep-set buoy gear $(D S B G)$, an artisanal gear type designed to target swordfish, Xiphias gladius, below the thermocline during the day. All trials were performed within the Southern California Bight (SCB) under an exempted fishery permit (EFP) recommended by the Pacific Fisheries Management Council (PFMC) and authorized by the $\mathrm{Na}$ tional Marine Fisheries Service (NMFS). Six cooperative fishermen were outfitted with uniform gear sets and performed 344 standardized deployments (10 individual buoys deployed for $8 \mathrm{~h}$ ) which produced 2,795 buoy soak hours. The collective catch resulted in a marketable catch rate of $\sim 97 \%$. Swordfish comprised $>80 \%$ of the total catch, with 611 individuals harvested over the two seasons of the EFP. Bigeye thresher sharks, Alopias superciliosus, were the second most common species totaling $\sim 16 \%$ of the EFP catch. The average daily swordfish catch rate was 1.75 swordfish $/ 8$-h set and varied by year and cooperative vessel. Catch rates and composition were similar to previous and concurrent research findings and contrasted shallow-set nocturnal buoy gear experiments performed during the same seasons. Nocturnal shallow-set research trials performed adjacent to EFP activities revealed low target ( 9\% swordfish) and high (>80\%) non-marketable catch. Juvenile blue sharks, Prionace glauca, made up $>76 \%$ of the total nocturnal catch. Collective DSBG trials to date suggest that daytime deep-setting within the $S C B$ may provide an additional opportunity for west coast fishermen to access a domestic resource. 
priorities have focused on the development of alternative harvest methods to increase domestic production and fisherman opportunity (Sepulveda et al., 2014). Fishery development within the CA EEZ is complicated by high conservation standards and the sensitivity associated with several of the bycatch species that spatially overlap with swordfish (e.g., leatherback and loggerhead, Caretta caretta, sea turtles as well as several marine mammals).

Other issues that have suppressed west coast fishery development include the continued prohibition of pelagic longline gear within the CA EEZ (Obrien and Sunada, 1994; West Coast Highly Migratory Species Fishery Management Plan, HMS FMP ${ }^{1}$ ). This prohibition has prevented the development and social acceptance of shallowset longline, the most common method used to harvest swordfish worldwide (Ward et al., 2000). Collectively, these conservation concerns have negatively impacted local swordfish production and continue to hinder the development of alternative methods for harvesting a domestic resource within the CA EEZ (Urbisci et al., 2016; Sepulveda et al., 2018).

In response to the decline in fishery participation and in accordance with Federal mandates (Magnuson-Stevens Fishery Conservation and Management Act, as amended ${ }^{2}$ ), the Pacific Fishery Management Council (PFMC) prioritized the development and trial of alternative methods for harvesting west coast swordfish. Among the gears proposed was deep-set buoy gear (DSBG), an artisanal "hook and line" technique developed for targeting swordfish within the SCB (Sepulveda et al., 2014). DSBG uses depth to selectively target swordfish below the thermocline during the day, a strategy that has been shown to reduce nontarget interactions in several deep-set longline fisheries around the world (Beverly and Robinson, 2004; Gilman et al., 2006, 2007).

\footnotetext{
${ }^{1}$ http://www.pcouncil.org/wp-content/uploads/ 2016/03/HMS-FMP-Mar16.pdf

${ }^{2} \mathrm{http}: / /$ www.nmfs.noaa.gov/sfa/magact/MSA_ Amended_2007\%20.pdf
}

Off California, deep-setting is of particular interest given that the waters are highly stratified with a relatively shallow thermocline (20-70 $\mathrm{m}$; Palacios et al., 2004) and oxygen minimum layer (350-400 m; Levin, 2003; Bograd et al., 2008). This suite of environmental conditions has been proposed to compress the amount of suitable habitat available for pelagic fish species, which may lead to enhanced targeting opportunities and gear performance (Prince and Goodyear, 2006).

Although DSBG has been shown to be effective at selectively targeting swordfish within the SCB (Sepulveda et al., 2014), questions concerning economic viability and cooperative interest remain untested. Additionally, it was unknown how DSBG catch and performance metrics produced under previous research application compared to commercial operations. Therefore, this study focused on 1) the field testing of DSBG by cooperative fishermen operating under an exempted fishery permit (EFP) recommended by the PFMC and issued through NMFS, and 2) expanding the scope of fishery development research for swordfish off southern California. Specifically, this work tested hypotheses related to the economic viability and catch performance of DSBG using data from six cooperative fishermen operating off the Southern California coast. Findings are presented and compared with concurrent research trials performed by the Pfleger Institute of Environmental Research (PIER). Collectively the body of work presented in this study is focused on the development and revitalization of the U.S. west coast swordfish fishery.

\section{Materials and Methods}

All cooperative fishing trials were performed under an exempted fishery permit (EFP) issued to lead investigator C. Sepulveda (PIER) through the PFMC on 18 of Aug. 2015 (PIER DSBG-EFP). EFP protocols were based on previous gear research and development trials conducted by PIER from 2011 to 2014 (Sepulveda et al.,
2014). All deployments, gear rigging, and set protocols followed the terms and conditions outlined in the PIER DSBG-EFP. Set locations were performed within the eastern portion of the SCB between Point Conception and the Mexico border (Fig. 1). All research experiments were conducted under a NMFS Letter of Acknowledgement issued by the NMFS West Coast Regional Office and a California Department of Fish and Wildlife (CDFW) Scientific Collection Permit (SPC-2471). To reduce seasonal variation the research trials presented in this work were performed concurrently with the PIER DSBG-EFP from 2015 to 2017, with catch being tagged and released (i.e., research catch did not contribute to EFP landings).

\section{Cooperative Fishermen Selection}

Cooperative fishermen participating in the PIER-DSBG EFP were chosen based upon a selection rubric for participation. Criteria used in the selection process included: availability during the primary California swordfish season (July-December), previous swordfish experience, willingness to cooperate and work as a unit, agreement to abide by all PIER and EFP mandated terms, and willingness to participate throughout the season regardless of gear performance. Selected participants had at least 10 years of swordfish fishing experience off California and an average participation history of 20 years. Cooperative fishermen also had valid swordfish permits, no recent history of fishing violations, and agreed to carry observers without objection. Based on the EFP terms and conditions, the EFP manager (PI Sepulveda) was held equally liable and responsible for the actions of the EFP participants.

\section{Deep-set Buoy Gear}

The DSBG design used in this study has been described previously in Sepulveda et al. (2014). For all cooperative fishermen participating in the PIER-DSBG-EFP, all sets of gear were designed by the EFP manager and measured to the nearest meter to 


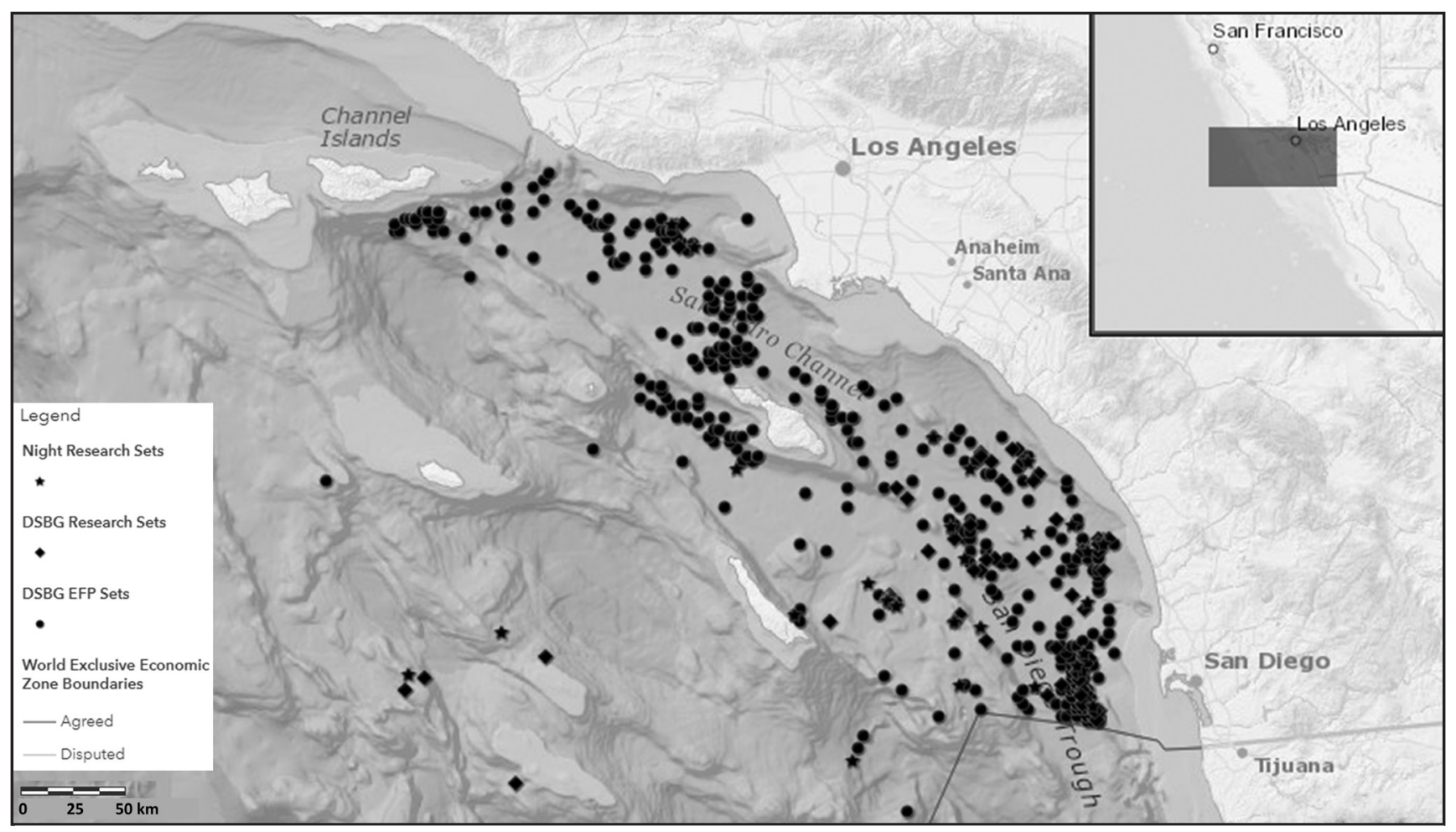

Figure 1.-Map of the Southern California Bight showing research and exempted trial deployments of deep-set buoy gear (DSBG) from June, 2014 to January, 2017.

ensure comparable rigging and performance. Briefly, the gear configuration consisted of a three-float system which included two strike-indicator floats $(3.2 \mathrm{~kg})$ and one large non-compressible longline float that was labelled with the vessel information $(21 \mathrm{~kg} ; 36$ cm dia.) (Sepulveda et al., 2014). The float system was affixed to a high-flyer flag and at least one form of locating device (i.e., radar reflector, strobe) to prevent gear loss and facilitate location at night.

Each piece of DSBG was designed to fish between 250 and $350 \mathrm{~m}$ with a terminal weight $(3.6 \mathrm{~kg})$ attached to each piece of gear. Gear sets were measured and configured by the PIER team prior to delivery to the EFP participants. Fishermen were given the option to fish up to a maximum of three hooks per individual piece of gear with a maximum of 10 individual pieces deployed at one time (maximum of 30 hooks soaking simultaneously). Gangions were approximately $8 \mathrm{~m}$ long and constructed of 1.8 to $2.0 \mathrm{~mm}$ monofilament leader with a crimped 18/0 circle hook (Mustad model 39960DT $\left.{ }^{3}\right)$. Battery-operated illumination (Power Light, SNL Corp., Florida) was used proximal to each gangion with fishermen given the choice of colors to be used (most deployments used either green or blue). Bait type consisted of either squid, Illex spp., or finfish such as chub mackerel, Scomber japonicus.

\section{Observation and EFP Monitoring}

Field observation of EFP activity was sourced through Saltwater Inc., Seattle, Wash., an independent fishery observer staffing contractor. Based on PFMC and NMFS terms and conditions, all EFP activities were to be monitored at a minimum rate of $30 \%$. The $30 \%$ coverage rate was granted for this study in response to 1) previous research trials which had docu-

\footnotetext{
${ }^{3}$ Mention of trade names or commercial companies is for identification purposes only and does not imply endorsement by the National Marine
} Fisheries Service, NOAA mented DSBG catch composition over the previous four years (Sepulveda et al., 2014), 2) the need for increased EFP effort and budget constraints, and 3 ) the additional monitoring and guidance provided by the EFP manager. To enhance data quality and increase confidence in reported catch during unobserved trips, the EFP coordinator required each vessel captain to comply with additional reporting requirements. These included deployment and return check-ins with NMFS, CDFW, and PIER as well as a daily catch reporting requirement. Daily reports were logged and compared to both vessel log sheets and landings records (see below section Catch and Bycatch Estimation).

Observer placement criteria consisted of initial assignment at the beginning of the season to build a coverage base for each vessel and subsequent assignment to a vessel if coverage reached a level of $35 \%$ to prevent vessels from falling below the minimum EFP coverage rate. Other consider- 
ations for carrying an observer included mandatory placement if the DGN gear type was going to be fished on the same fishing trip. Lastly, vessel operators could not decline the placement of an observer for any reason.

Custom observer and vessel log sheets were designed in conjunction with the NMFS Fisheries West Coast Observer Program coordinator (C. Villafana, NMFS-West Coast Region, WCR) to capture additional environmental information associated with deployments. Landings were monitored using traditional CDFW landings receipts, logbook records, and identification tags affixed around the collar of landed catch. Identification tags were instituted in year two of the EFP and contained a product code and vessel name that allowed consumers to better track DSBG product as it moved through the market chain. Identification tags were instituted in response to market and consumer requests voiced in year 1 of the EFP.

\section{EFP Deployment Conditions}

In an attempt to mimic commercial fishing conditions to the extent possible, cooperative fishermen were given the liberty to deploy DSBG when and where they wanted as long as the configuration of the gear was not altered and deployment location fell within the action area of the terms and conditions of the PIER-DSBG-EFP. Daily set location, duration of set, and quantity of gear deployed was left up to the discretion of the EFP participant. In accordance with the EFP terms and conditions, DSBG could not be deployed prior to sunrise and the participant had to commence gear haul-back procedures prior to sunset, thus providing a theoretical maximum set duration.

\section{Catch and Bycatch Estimation}

All catch was enumerated using both vessel and observer log sheet entries and CDFW landings receipts. Vessel log sheets were compared with checkin reports and observer logs to ensure that fishing dates and times, catch statistics, and non-target species interactions were consistent. If discrepancies were identified, then individual fishermen were contacted directly to confirm or correct uncertainties (for the entire 2 year EFP (4,084 buoy deployments) this was estimated to be less than 8 instances). Target and non-target catch rates were summarized from actual data and reported to management agencies in both raw and standardized form. Standardization was performed to account for short sets (1-3 h) and to allow for effort comparisons among other gear types (i.e. longline and DGN soak times) as well as previous DSBG fishing trials (Sepulveda et al., 2014). The standardized set metric defined a fishing day as 10 pieces of buoy gear fished over an 8-h period, which closely approximated average deployment parameters for both the EFP and research trials.

Non-target species catch was further classified into either marketable or non-marketable species (i.e., species that did not have a market history off the west coast) to assess DSBG selectivity and potential discard rates. Estimates for sensitive species bycatch, including marine mammals and species with extended federal or state protection (i.e., threatened or endangered), were calculated for both observed and extrapolated values. The extrapolation procedure took into account total effort (number of set days) and observer coverage rates to generate the extrapolated bycatch estimate. Extrapolation procedures were also performed for other non-marketable species (i.e. blue sharks, Prionace glauca; Table 2) and not used for marketable catch, as the reporting statistics were validated with landings receipts and presumed to be accurate for marketable species (Urbisci et al., 2016).

\section{Research Sets}

In addition to the EFP deployments, DSBG research trials were conducted off southern California by PIER onboard the research vessel R/V Malolo from June 2014 through December 2016 to further evaluate gear performance, test for differences in day vs. night catch composition, and to conduct tagging experiments. Initial
DSBG research and development trials conducted from 2011 to 2013 were analyzed separately for catch composition and effort (Sepulveda et al., 2014). As with previous experimental deployments, most of the research sets utilized three hooks per piece of buoy gear. Based on EFP terms and conditions, experimental DSBG catch and effort metrics were calculated and reported independent of the cooperative EFP trials (PIER DSBG-EFP).

In addition, concurrent nocturnal shallow-set experiments (shallow set buoy gear, SSBG) were conducted within the same areas and times as the daytime PIER research trials and EFP deployments. Nocturnal catch data were recorded using the same logbook forms and used to compare catch composition between deep-day and shallow-night setting. Similar to the DSBG deployments, night set depths were based on swordfish movement data from the study area (Sepulveda et al., 2010, 2014) and traditional swordfish longline methods currently used outside of the CA EEZ. Circle hooks (18/0 Mustad model 39960DT) were positioned within the upper mixed layer at night (between the surface and the thermocline; 10 to $60 \mathrm{~m}$ ) with a mean hook depth of $\sim 24 \mathrm{~m}$. Hook depth was verified by a depth logger that was affixed to each gangion (CEFAS Tech. Ltd.; Lowestoft, U.K.). Nocturnal sets were constructed of the same gear and materials used in the daytime trials (DSBG), as one of the goals was to assess feasibility of concurrent shallow and deep-set deployments (DSBG).

The shallow-set configuration was very similar to the DSBG design with less vertical mainline and a shallower hook position. The configuration used $3.6 \mathrm{~kg}$ weights, strike indicator buoys, and an illumination source proximal to each branched $8 \mathrm{~m}$ gangion $(1.8 \mathrm{~mm}$ monofilament). Terminal gear was similar to that used in the DSBG trials except that the terms and conditions of the research trials precluded the use of squid for any shallow set experiments. Set location parameters were based on daily cooperative vessel input and were principally conducted in areas of 
temperature and productivity convergence (Sepulveda et al., 2014).

Each nocturnal set consisted of 10 to 30 hooks deployed for a minimum of $4 \mathrm{~h}$ between the hours of sunset and sunrise. For comparison with the PIER DSBG-EFP and research trial data, night sets were standardized based on an 8-h soak period. Similar to daytime DSBG efforts, gear was actively monitored for strikes and serviced upon detection of a fish on the line. If catch was detected, gear was hauled and the catch was measured, tagged with either a conventional or electronic tag, and released. Bait predation was documented at the time of haul-back for all research sets and was defined as any instance in which $50 \%$ or more of the bait was mutilated or consumed during the soak period.

\section{Data Analyses}

Monthly logbook entries were entered into an Excel spreadsheet and summarized by vessel prior to generating collective summaries. Only catch that was retained for sale or released at the vessel were considered in the catch assessments. To provide a consistent and comparable estimate of fishing effort, data was examined by the number of sets, buoys deployed, and soak hours to calculate the number of "standardized" set days. The 10 buoy and 8-h standardized metric was chosen because it closely mirrored the daily average soak time and number of buoys deployed for the entire PIER DSBG-EFP. It also provided a consistent set metric for comparing research and EFP activities. Market price estimates were based upon average ex-vessel price recorded by the cooperative fishermen at the time of offloading.

\section{Economic Analyses}

To preliminarily assess the cost of DSBG activities while under exempted testing, a survey was provided to cooperating fishermen following the Year 2 trials. The survey was voluntary and consisted of a series of questions aimed at estimating the daily expenditures associated with a typical DSBG fishing day. Vessels were excluded from the analysis if vessel size was not consistent with the size range likely to participate in a commercial DSBG fishery, if the vessel did not participate in the EFP throughout the entire season, or if they were reluctant to provide financial information.

Responses from participating vessels were averaged among the group to ensure anonymity and daily cost estimates were based on the average number of set days per vessel in Year 2 ( $n$ $=56$ ). Because cooperative fishermen participating in the EFP are portfolio fishermen who participate in several independent fisheries throughout the year, fixed costs (i.e., insurance, slip fees) were considered only for the swordfish fishing season (6 mo, JulyJanuary). Also, given that all of the participants own their vessels outright, vessel financing was not considered in the cursory analyses. Given that all fishermen sold to the same market and because price did not vary considerably among EFP vessels, average fish price was not weighted. Estimates of daily and seasonal profits were also not calculated given that trip length varied widely and because gear set-up was subsidized through the projects funding sources.

\section{Tagging}

To assess short-term vertical movements of the primary non-marketable species encountered during nocturnal research trials, two blue sharks (1.4 to $2.1 \mathrm{~m}$ (fork length) FL) were tagged with short-term satellite tags (Wildlife Computers, Richmond, Wash.; Mini-Pat) prior to release. Tags were programmed for $<30$ days to ensure that all the archived time-series data could be transmitted through the Argos Network and data resolution was sufficient to compare diel movement patterns between target (i.e., swordfish) and non-target species (i.e., blue sharks). The depth statistics from the blue shark tags were compared with the tracks from two tagged swordfish (130 and $152 \mathrm{~cm} \mathrm{FL)} \mathrm{that} \mathrm{were} \mathrm{also}$ tagged within the same geographic area and season.

\section{Results}

\section{PIER DSBG-EFP Effort and Location}

This work reports on the first two seasons of exempted trials of DSBG aboard cooperative vessels from 2 Sept. 2015 through 10 Jan. 2016 (Year 1) and from 25 May 2016 through 9 Jan. 2017 (Year 2). Fishing effort and distribution was constrained by the terms and conditions of the PIER DSBG-EFP. Set locations occurred primarily in the south and eastern portion of the SCB, from Point Conception, $\mathrm{CA}\left(34^{\circ} 27^{\prime} \mathrm{N}\right.$ and $\left.120^{\circ} 28^{\prime} \mathrm{W}\right)$ to the Mexican border (Fig. 1).

Overall six cooperative fishing vessels participated in the initial two years of the EFP, with four vessels participating in Year 1 and five fishing during Year 2. In Year 1, vessels were not cleared for fishing until late August, which resulted in $95 \%$ of fishing effort occurring September through December. In year two, the effort was more evenly distributed throughout the season, with fishing activity spread from July through December. For the two years, (September, 2015 to January, 2017), 417 DSBG set days were reported over the course of 113 independent fishing trips, with a mean trip duration of 3.65 days/trip. During the two seasons, the total number of sets per vessel ranged from 43 to 127 (mean=69.5 sets/vessel) which resulted in a total of 4,084 pieces of DSBG deployed during the study period.

Although cooperative fishermen had the option to deploy up to three hooks per piece of gear, $>95 \%$ of EFP sets were deployed using only one baited hook per buoy, a strategy that reduced tangling of the upper gangions. The collective EFP activities yielded 27,535 buoy-soak hours, with an average of 9.8 buoys deployed per set. Daily soak times varied by vessel and season with annual averages ranging from $6.3-7.6 \mathrm{~h} / \mathrm{set}$; with a collective mean of $6.7 \mathrm{~h} / \mathrm{set}$. For comparison purposes, set days were standardized to 8-h soak days or 349 8-h fishing days. To compare metrics of catch per unit effort, the data were also standardized 
Table 1.-Annual statistics for the total number of observed and unobserved sets for each cooperative fishing vessel that participated in the PIER deep set buoy gear exempted trials (DSBG EFP) and associated observer coverage rates for the $\mathbf{2 0 1 5 - 1 6}$ fishing seasons.

\begin{tabular}{lccccc}
\hline EFP Vessel & $\begin{array}{c}2015 \\
\text { \# set days }\end{array}$ & $\begin{array}{c}2016 \\
\text { \# set days }\end{array}$ & $\begin{array}{c}\text { Total } \\
\text { \# set days }\end{array}$ & $\begin{array}{c}\text { Total } \\
\text { \# observed sets }\end{array}$ & $\begin{array}{c}\text { Observer } \\
\text { coverage rate }\end{array}$ \\
\hline FN Chula & 50 & 0 & 50 & 19 & $38 \%$ \\
FN Gold Coast & 46 & 81 & 127 & 47 & $37 \%$ \\
FN Three Boys & 28 & 35 & 63 & 26 & $41 \%$ \\
FN Spirit & 14 & 45 & 59 & 27 & $46 \%$ \\
FN Leah Gail & 0 & 75 & 75 & 30 & $40 \%$ \\
FN Aurelia & 0 & 43 & 43 & $\underline{21}$ & $41 \%$ \\
Total/Mean & $\mathbf{2 1 3}$ & $\mathbf{4 1 7}$ & & & $41 \%$ \\
\hline
\end{tabular}

to a full 10 buoy complement, which yielded a collective effort estimate of 344 8-h fishing days. Over the course of the study, there was only one piece of DSBG lost at sea following a mechanical breakdown aboard one of the cooperative vessels.

\section{Observation and Catch Monitoring}

Collectively, 170 set days were observed by NMFS-certified monitors, resulting in an overall observer coverage rate of $41 \%$ for the two year EFP period (Table 1). In Year 1, the average coverage rate for the entire EFP group was $46 \%$ (range $38-79 \%$ ) and in Year 2 the average coverage was $38 \%$ (range 35-49\%). Observer coverage was consistently maintained above $35 \%$ on all EFP vessels throughout all EFP deployments.

\section{Catch}

During the initial two years of the PIER DSBG-EFP, catch was com- prised of seven species, with swordfish making up $>80 \%$ of the total catch. Other marketable species, included opah, Lampris guttatus; bigeye thresher shark (BET), Alopias superciliosus; mako shark, Isurus oxyrinchus; and escolar, Gempylidae; which comprised an additional $18.0 \%$ of total catch (Table 2, Fig. 2a). Non-marketable catch (i.e., species not typically retained for sale in the California fishery) comprised $1.2 \%$ of the total catch and consisted of eight blue sharks and one northern elephant seal, Mirounga angustirostris. The northern elephant seal interaction took place during an observed set. The hook was reported to be in the upper lip near the corner of the mouth and the elephant seal was described as "alive and alert" upon release. The observer records also reported that the hook was shed from the animal prior to swimming away. Based on the single elephant seal interaction and a collective EFP observation rate of $41 \%$, the extrapolated interaction estimate was 2.5 individuals for the study period. Because the northern elephant seal was observed to be "alive and alert" upon release, no further estimates of fishing mortality were calculated. Because there was no observed blue shark catch (i.e. all 8 blue sharks were self-reported during nonobserved trips), the extrapolated value for blue sharks was 0 .

Collectively, 611 swordfish were caught over the two-year EFP period. Average swordfish size was consistent with ongoing harpoon and DGN operations, with a mean estimated dressed weight of $62.3 \mathrm{~kg}$ (range 11-205 kg). Based on mean estimated size, total swordfish landings for the six cooperative vessels was estimated to be approximately $38 \mathrm{t}$ dressed weight, which is equivalent to approximately $48 \mathrm{t}$ round weight (Uchiyama et al., 1999). Average ex-vessel price for swordfish in the PIER DSBG-EFP was approximately $\$ 7.50 / \mathrm{lb}$.

Catch rates varied by vessel and year, with an overall average of 1.75 swordfish/8-h soak period. The nonstandardized catch rate for the EFP period based on a reduced soak period was 1.47 swordfish/6.7-h soak. In 2015, daily average catch rates ranged across vessels from 0.6 to 1.6 (mean=1.4 swordfish/8-h set), while in 2016 catch rates ranged from 1.3

Table 2.-Catch statistics (based on actual and extrapolated values) for all deep set buoy gear (DSBG) deployments conducted between June, 2014 and January, 2017 onboard the PIER research vessel and six cooperative fishing vessels that operated under exempted status in the PIER DSBG EFP. Extrapolated catch values are only applied to non-marketable species caught aboard cooperative vessels.

\begin{tabular}{|c|c|c|c|c|c|c|c|}
\hline Catch Species & $\begin{array}{l}\text { PIER research } \\
\text { catch }(2014-16)\end{array}$ & $\begin{array}{l}\text { Research } \\
\text { catch (\%) }\end{array}$ & $\begin{array}{c}\text { DSBG EFP } \\
\text { catch (2015-16) }\end{array}$ & $\begin{array}{l}\text { Extrapolated } \\
\text { catch }\end{array}$ & $\begin{array}{c}\text { EFP } \\
\text { catch (\%) }\end{array}$ & $\begin{array}{l}\text { PIER nocturnal } \\
\text { research } \\
\text { catch }(2014-17)\end{array}$ & $\begin{array}{l}\text { Nocturnal } \\
\text { research } \\
\text { catch (\%) }\end{array}$ \\
\hline Swordfish & 59 & $57.8 \%$ & 611 & NA & $80.9 \%$ & 8 & $9.4 \%$ \\
\hline Opah & 8 & $7.8 \%$ & 3 & NA & $0.4 \%$ & 0 & $0.0 \%$ \\
\hline Bigeye thresher & 23 & $22.5 \%$ & 123 & NA & $16.2 \%$ & 1 & $1.2 \%$ \\
\hline Common thresher & 2 & $2.0 \%$ & 0 & NA & $0.0 \%$ & 0 & $0.0 \%$ \\
\hline Shortfin mako shark & 2 & $2.0 \%$ & 1 & NA & $0.1 \%$ & 8 & $9.4 \%$ \\
\hline Gempylidae spp. & 2 & $2.0 \%$ & 9 & NA & $1.2 \%$ & 0 & $0.0 \%$ \\
\hline Yellowfin tuna & 1 & $1.0 \%$ & 0 & NA & $0.0 \%$ & 0 & $0.0 \%$ \\
\hline Blue shark & 4 & $3.9 \%$ & 8 & 0 & $1.1 \%$ & 65 & $76.5 \%$ \\
\hline Smooth hammerhead & 0 & $0.0 \%$ & 0 & NA & $0.0 \%$ & 2 & $2.4 \%$ \\
\hline \multicolumn{8}{|l|}{ Species with protection } \\
\hline Northern elephant seal ${ }^{1}$ & 1 & $1.0 \%$ & 1 & 2.5 & $0.1 \%$ & 0 & $0.0 \%$ \\
\hline California sea lion ${ }^{1}$ & 0 & $0.0 \%$ & 0 & NA & $0.0 \%$ & 1 & $1.2 \%$ \\
\hline Other protected species & 0 & $0.0 \%$ & 0 & 0 & $0.0 \%$ & 0 & $0.0 \%$ \\
\hline Total catch (no. of individuals) & 102 & & 756 & & & 85 & \\
\hline No. standardized 8-h set days & 40.5 & & 344 & & & & \\
\hline
\end{tabular}

${ }^{1}$ Released alive and alert. 

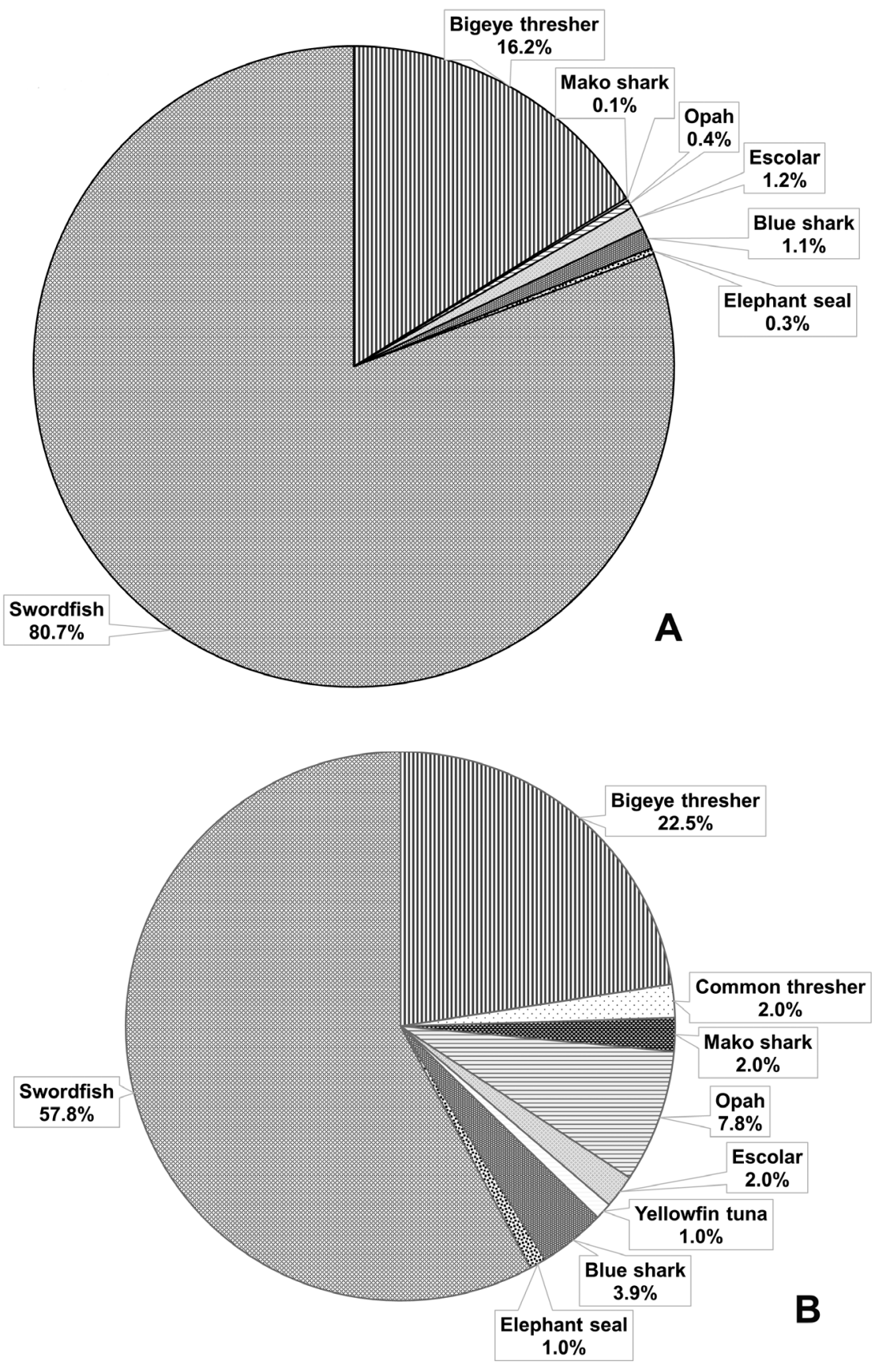

Figure 2.-A. Catch composition for six cooperative fishing vessels during 417 deep-set buoy gear (DSBG) deployments under the PIER DSBG EFP trials throughout the 2015-16 seasons.

B. Catch composition of 40.5 standardized 8-hr deep-set buoy gear (DSBG) research deployments within the Southern California Bight onboard the PIER R/V Malolo during the 2014-16 seasons.

C. On next page. to 2.9 (mean=1.9 swordfish/8-h set). In 2015 and 2016 the month with the highest swordfish catch was October.

BET sharks were the second most common species encountered in the 2-yr. EFP and comprised $16.2 \%$ of the total catch. BET ranged in estimated weight from 45 to $170 \mathrm{~kg}$, with an average round weight of $\sim 90 \mathrm{~kg}$. Log sheet entries indicated that all BET were alive at the time of capture, and that $76 \%$ were released and $24 \%$ $(n=29)$ were retained for sale. Observer and vessel $\log$ sheets indicated that large BET $(>100 \mathrm{~kg})$ were typically released, as it was noted that that smaller individuals were more readily handled and marketed. Ex-vessel price for BET ranged from $\$ 0.50$ to $3.50 / \mathrm{lb}$, with an average of $\sim \$ 2.25 / \mathrm{lb}$. Despite the use of circle hooks, hooking location for BET varied and consisted of the mouth, pectoral fin, and the caudal fin.

\section{Economic Analyses}

The average daily operating cost of a DSBG trip day aboard a 13-16 m single engine diesel vessel operating in the PIER DSBG-EFP was approximately $\$ 477 \pm 79 /$ day (Table 3). Average compensation for a single crew member was approximately $20 \pm 2 \%$ of the trip's net profit, and all vessels participating in the survey used only one crew member throughout the EFP period. Based on the average size of fish (62.3 kg or $137 \mathrm{lb}$ dressed weight), average price/lb $(\$ 7.50 / \mathrm{lb})$ and average catch rates for the entire EFP period (1.75 swordfish/8-h day), an estimation of the average daily net income from one day's fishing activity was approximately $\$ 1,087$ (daily estimate excludes gear setup, vessel amortization, and travel days; see Methods for more details).

\section{Research Sets}

A total of 40.5 standardized (10 pieces of DSBG) 8-h fishing days were conducted aboard the PIER research vessel R/V Malolo from 2014 to 2016. Catch composition during PIER DSBG research sets consisted of nine species, which included the same 


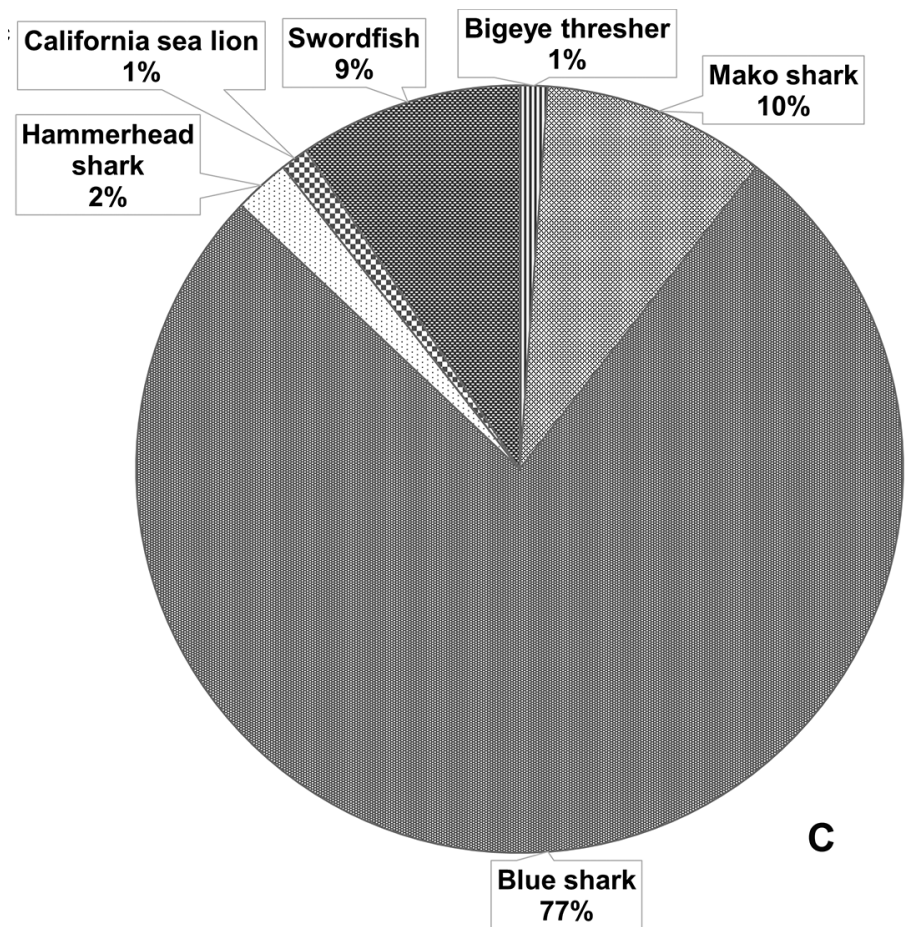

Figure 2.- C. Catch composition from 30 nocturnal shallow-set deployments off southern California onboard the PIER research vessel R/V Malolo from 2014-17.

Table 3.-An estimate of daily fisherman expenses based on participation surveys provided by three participants of the exempted trials. Costs reflect daily expenses based on the 2015-16 fishing season (six months) and the average number of days each vessel fished (56 days).

\begin{tabular}{lcccccccc}
\hline Meals & $\begin{array}{c}\text { Mooring } \\
\text { costs }\end{array}$ & $\begin{array}{c}\text { Insurance } \\
\text { costs }\end{array}$ & $\begin{array}{c}\text { Crew \% of } \\
\text { trip net }\end{array}$ & $\begin{array}{c}\text { Vessel } \\
\text { fuel }\end{array}$ & $\begin{array}{c}\text { Bait \& } \\
\text { supplies }\end{array}$ & $\begin{array}{c}\text { Onboard } \\
\text { communications }\end{array}$ & $\begin{array}{c}\text { Vessel } \\
\text { maintenance }\end{array}$ & $\begin{array}{c}\text { Daily } \\
\text { expense } \\
\text { estimate }\end{array}$ \\
\hline $56 \pm 15$ & $16 \pm 1$ & $46 \pm 25$ & $17 \pm .025 \%$ & $135 \pm 15$ & $103 \pm 45$ & $13 \pm 7$ & $106 \pm 11$ & $477 \pm 79$ \\
\hline
\end{tabular}

seven species captured in the EFP trials, as well as the common thresher shark, Alopias vulpinus ( $n=2)$ and yellowfin tuna, Thunnus albacares $(n=1)$. Swordfish comprised $58 \%$ of the catch during research trials and other marketable species made up an additional $37 \%$ of the experimental catch $(95 \%$ marketable catch) (Table 2, Fig. 2b). Despite a more diverse assemblage of species caught during the research sets, standardized daily swordfish catch rates were similar for both research (mean=1.50 swordfish/8-h day) and EFP trials (mean=1.75 swordfish/8$\mathrm{h}$ day). Incidental catch consisted of four blue sharks and a single northern elephant seal that was released alive and in good condition (hook was left in place and the line was cut near the hook to reduce trailing gear). With the exception of swordfish, bigeye thresher sharks, escolar, and the northern elephant seal, all other species captured during the trials occurred on the shallowest hook (90-100 m depth).

Nocturnal research sets were also conducted from September 2014 through January 2017 on 30 different nights with an average soak time of 6.2 $\mathrm{h} / \mathrm{set}$. Sets were based on times and locations in which swordfish were present (based on concurrent daytime EFP and DGN fishing activity). Nocturnal sets typically occurred at the same general location that a daytime EFP or research DSBG set had occurred. Seasurface temperatures ranged from 16.5 to $25.0^{\circ} \mathrm{C}$.

On average, 15.2 baited hooks were deployed per set at an average depth of $24 \mathrm{~m}$ (range 12-30 m) yielding a total of 2,997 hook soak hours. Eight swordfish were captured during nocturnal sets, which equated to approximately $9 \%$ of the total catch or 0.36 swordfish per 8-h set (Table 2, Fig. 2C). Other marketable species, including mako sharks and bigeye thresher sharks, comprised an additional 11\% of the catch, resulting in a total marketable catch rate of $\sim 20 \%$.

The primary species encountered during nocturnal sets was the blue shark $(76 \%$ of the catch), a species currently not marketed in the California fishery. A single California sea lion, Zalophus californianus, was also captured and released alive and alert following a brief $(15 \mathrm{~min})$ period on the line. Bait predation by California sea lions and other surface-oriented species (primarily pelagic sharks) occurred on $24 \%$ of baited hooks over the course of the study. For three of the sets, bait predation occurred on every hook that did not have a hooked blue shark or mako shark.

\section{Tagging Data}

Two blue sharks captured during nocturnal gear trials were opportunistically tagged to assess depth and temperature distribution within the study area. Mean night depth of the $136 \mathrm{~cm}$ and $205 \mathrm{~cm}$ FL blue sharks was $15.2 \pm$ $16 \mathrm{~m}$ and $4.4 \pm 4 \mathrm{~m}$, respectively, with nearly all of the nocturnal records remaining consistently within the upper mixed layer. Daytime depth was more variable with routine bounce dives below the thermocline, with average daytime depths of $40.8 \pm 8 \mathrm{~m}$ and $16.7 \pm$ $30 \mathrm{~m}$ (Fig. 3).

Nocturnal trends of the two tagged blue sharks follow those of previous studies and suggest less variability at night, with $99.9 \%$ of the time spent above the average depth of the thermocline ( $\sim 50 \mathrm{~m}$; Fig. 3). When compared 


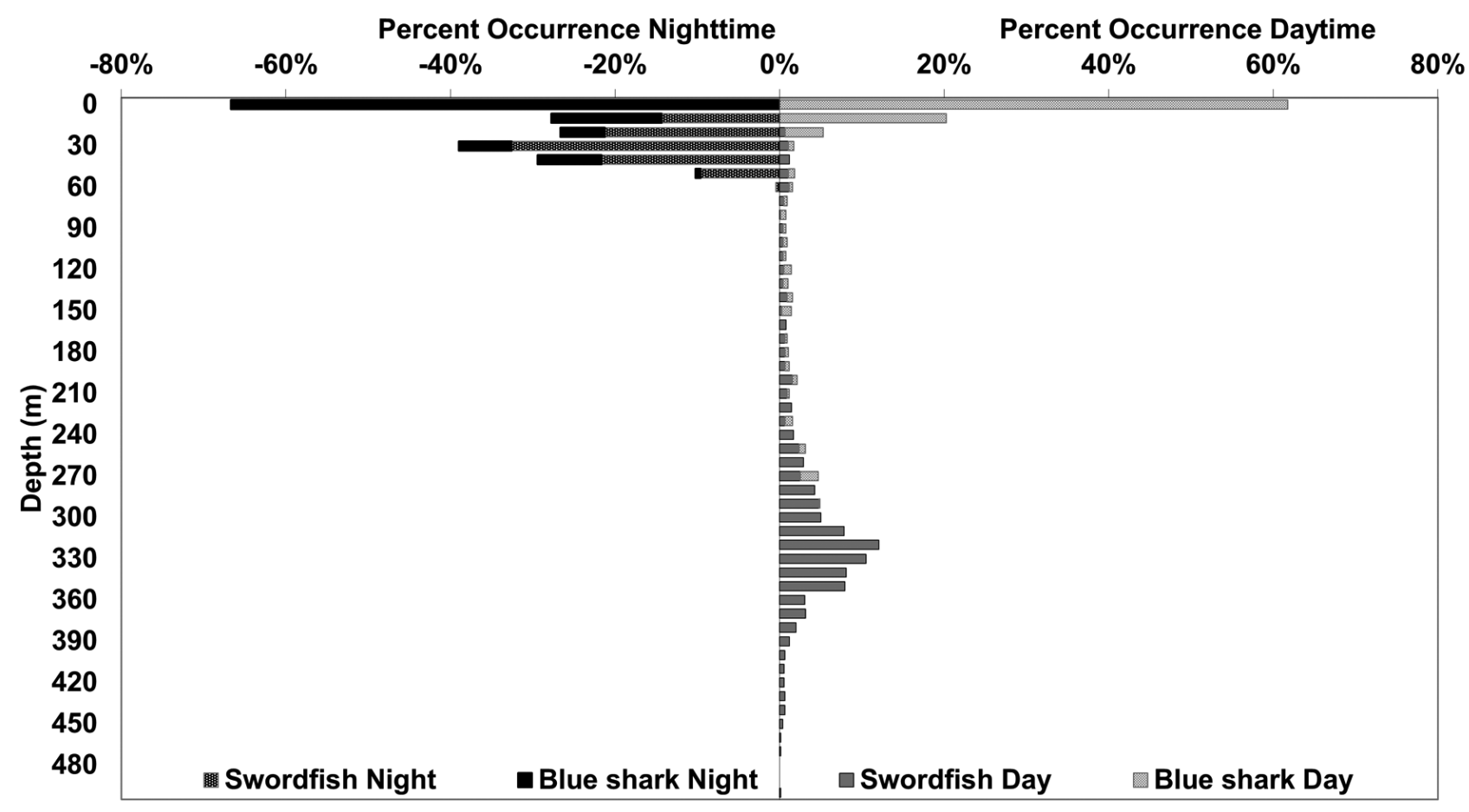

Figure 3.-Day and nighttime depth profiles summarized into 10-m bins from time series data collected during electronic tag deployments on two swordfish (130 and 152-cm fork length, FL) and two blue sharks (136 and 205-cm FL) off southern California in 2016-17.

to the two swordfish tagged in the same area (130 and $152 \mathrm{~cm} \mathrm{FL)} \mathrm{and}$ same time period, there was significant nocturnal overlap, with swordfish having an average night depth of 42.2 $\pm 9 \mathrm{~m}$ and $25.0 \pm 8 \mathrm{~m}$, respectively (Fig. 3). As previously shown, during the daylight hours swordfish remained predominantly below the thermocline, spending $97.1 \%$ of the day below the average depth of the thermocline ( $\sim 50$ m) (Fig. 3).

\section{Discussion}

This study focused on the testing of alternative fishing techniques for swordfish off Southern California from both cooperative and research vessel applications. Data corroborate previous findings and suggest that deep-setting during the day can result in high selectivity for swordfish off Southern California (Sepulveda et al., 2014). The EFP trials revealed similar swordfish catch rates and catch composition to that of simultaneous and previous DSBG research trials, while concur- rent experiments comparing deep-day and shallow-night techniques within the same study area identified selectivity differences.

Given that the study area had high spatial overlap between swordfish and pelagic sharks (within the upper mixed layer at night), this study was not able to identify how nocturnal shallow-set operations can be modified to increase selectivity for swordfish. However, this work does provide support for the continued trial and use of deep-set daytime techniques with preliminary data suggesting that DSBG may provide west coast fishermen with a selective option for domestic swordfish harvest.

\section{Set Times and Locations}

PIER DSBG-EFP set locations align with historical set and catch data for both the DGN and harpoon fleets that continue to operate within the SCB (Hanan et al., 1993; Coan et al., 1998). Seasonal set locations and fleet movements followed the trends typical of the historic DGN fishery, which follow frontal edges of both temperature and productivity (Hanan et al., 1993; Sepulveda et al., 2010). Cooperative fishermen set criteria varied extensively among participants, and typically entailed the combination of oceanographic conditions, historical fishing performance, ongoing fishing activity, and proximity to home port.

In September 2015, cooperative fishermen initiated deployments upon PIER DSBG-EFP authorization, which was approximately 2 months into the fishing season. In 2016, the EFP team was allowed to initiate deployments at their own volition, with initial sets performed in May. The first deployments coincided with the onset of summer conditions and the first sightings of swordfish by the commercial harpoon fleet (Fukushima ${ }^{4}$ ). During May and June of 2016, EFP participants exhibited a lull in DSBG activity as most of

\footnotetext{
${ }^{4}$ Fukushima, K. Cooperative swordfish fisherman, San Diego, Calif. Personal commun., Sept. 2016.
} 
the vessels were more focused on the use of harpoon methods. DSBG catch and effort subsequently increased as harpoon catch and effort declined in July. Opportunistic harpooning of swordfish ensued throughout the duration of the trials by all EFP participants suggesting the complimentary nature of DSBG and harpoon operations in any future fishery.

\section{Catch Composition}

Swordfish comprised $>80 \%$ of EFP catch, a selectivity value that is higher than both longline and DGN fisheries and lower than harpoon operations which typically have zero bycatch as they directly target swordfish swimming at the surface (Hanan et al., 1993; Coan et al., 1998; WCPFC, 2014; PFMC, 2017). Other nonmarketable species comprised $<2 \%$ of the total EFP catch, consisting of only two species that are also incidentally caught in other fisheries within the SCB (Hanan et al., 1993; Obrien and Sunada, 1994). Catch composition over the two years of the EFP was found to be similar to concurrent and previous research trials spanning from 2011 to 2017 (Sepulveda et al., 2014; this study). The inter-annual consistency in catch composition is likely due to the relatively stable environmental conditions experienced at depth in the $\mathrm{SCB}$ (i.e., temperature, $\mathrm{O}_{2}$ saturation), and the reduced tolerance to these conditions exhibited by most pelagic species (Levin, 2003; Bernal et al., 2009).

Selectivity for swordfish in the EFP trials was slightly higher than previous and concurrent research trials (Sepulveda et al., 2014). This difference is likely a product of the hook placement protocols, as the EFP terms and conditions did not mandate that cooperative fishermen deploy all three hooks. Because cooperative fishermen were primarily interested in the most profitable target (swordfish) and because the upper hooks had a greater tendency to tangle, $>95 \%$ of the EFP deployments consisted of a single baited hook at the terminal end of the weighted vertical mainline. Similar trends have been reported in the Florida buoy fish- ery (a shallow-set nocturnal operation), where fishermen typically use one hook when regulations allow two hooks per buoy (Burlew ${ }^{5}$ ).

Throughout the trials, the deepest (terminal) hook position has consistently produced the highest swordfish and bigeye thresher catch, while the upper-most hook position $(\sim 100 \mathrm{~m})$ used to target opah has consistently yielded the highest non-swordfish catch to date (Sepulveda et al., 2014; this study). The DSBG research trials performed during this work employed a configuration that used all three of the baited hooks on each vertical mainline. If the EFP and research trials are compared using only the catch from the terminal hook, both groups had similar catch composition and marketable catch rates.

The BET shark was the second most common species caught in the PIER DSBG-EFP comprising $\sim 16 \%$ of the total catch. It is a deep-dwelling species that shares a comparable diurnal depth distribution to that of swordfish (Nakano et al., 1997; Weng and Block, 2004; Sepulveda and Aalbers ${ }^{6}$ ). During the EFP trials it was observed that most of the BET captures occurred during sets near bathymetric features, a consideration that likely led to increased avoidance in Year 2 of the EFP. Of the 123 BET that were captured in the EFP, 24\% were brought to market and the remainder were released alive.

To better assess DSBG impacts on the BET resource, tagging experiments were performed to assess post release disposition, with initial data suggesting high survivorship ( $n=14, \sim 90 \%$ survival rate; Sepulveda and Aalbers ${ }^{6}$ ). Bigeye thresher retention rates were dictated by the cooperative fishermen history of selling BET, hold space, and market dynamics. Early in the season or when swordfish catch rates were low, cooperative fishermen tended to retain more of the captured BET, while

${ }^{5}$ Burlew, C. Commercial buoy fisherman, Deerfield, FL, Personal commun., 9/2015

${ }^{6}$ Sepulveda and Aalbers. Depth distribution and post release survivorship of bigeye thresher sharks. Manuscript on file at the Pfleger Institute of Environmental Research. they were almost all released when fishing for swordfish was good.

The two years of EFP deployments encompassed both strong El Nino Southern Oscillation (ENSO; Year 1) periods and ENSO-neutral conditions (Year 2). Despite differences in oceanographic conditions (i.e., sea surface temperatures, productivity), both years had similar catch composition, with the only notable difference being that Year 1 had a higher BET catch than Year 2. It is difficult to ascertain whether the increased BET catch was due to different environmental conditions, local shark abundance, or fisherman behavior (i.e., avoidance).

\section{Catch rates}

Although catch rates between different gear types are difficult to compare, swordfish catch during the PIER DSBG-EFP was within the range of daily catch rates for other California swordfish fisheries (i.e., DGN and harpoon). Swordfish landings from California harpoon vessels have historically fluctuated widely from 0.14 to 0.93 swordfish harvested per vessel day and are largely dependent upon regional oceanic conditions (Coan et al., 1998). Although California DGN vessels occasionally report catches of $>30$ swordfish in one night set, mean daily catch rates have been reported to range between 1 to 3 swordfish/set (Coan et al., 1998), a rate that is within the range of values observed in this study. Comparable catch rates are likely because both DSBG and DGN operate on a similar horizontal scale (1 nmi of net vs. 1 to $3 \mathrm{nmi}$ footprint for DSBG) in an area where the swordfish resource is condensed into regional areas of productivity.

Similarly, the Florida shallow-set buoy fishery also operates in an area that is known for aggregating large numbers of swordfish (Kerstetter and Bayse, 2009). Although daily catch statistics for the Florida fishery are difficult to calculate from published literature, data obtained from an initial pilot study suggests catch rates to be similar to those of this study. In the Florida fishery, Kerstetter and 
Bayse (2009) reported catches of $\sim 202$ swordfish $/ 1,000$ hooks while retained catch was on the order of $\sim 145$ swordfish/1,000 hooks (juvenile swordfish below 119-cm FL must be released). When compared to this study, the standardized catch estimate based on an 8 h soak period would be $\sim 175$ retained swordfish/1,000 hooks while the nonstandardized estimate based on a $6.7 \mathrm{~h}$ soak would be $\sim 147$ swordfish/1,000 hooks.

As noted by Kerstetter and Bayse (2009), it is difficult to draw direct comparisons between catch rates on either shallow or deep-set buoy gear with longline catch rates, as they operate on different scales, deploy proportionally different numbers of hooks/ set, have different soak times, and operate in different areas. However, in terms of number of swordfish per 1,000 hooks, both Florida shallow-set buoy gear and DSBG in this study exhibit a higher relative catch per unit effort (no. of fish/1,000 hooks) with lower overall volume captured compared to either the Atlantic or Hawaiian shallow-set longline fisheries. For example, results from this study suggest approximately 175 swordfish captured for every 1,000 hooks deployed for $8 \mathrm{~h}$, while average catches in the Hawaii-based longline fishery range from 8-16 swordfish/1,000 hooks deployed (WCPFC, 2014).

\section{Economic Analyses}

Due to the low number of hooks deployed per day, economic viability has remained a concern for both managers and fishermen alike. Based on a cursory estimate of trip expenses, catch rates, and ex-vessel price, it was assumed that DSBG likely achieved economic viability during most of the EFP trips. This was also evidenced by fishermen continuing to use DSBG when they had access to other fisheries, including DGN. Based on an evaluation of price point, catch rate, and vessel operating costs, it was estimated that fishermen must land, on average, at least one swordfish per day in order to meet minimum trip expenses. This finding is similar to that discussed by Coan et al. (1998) for the harpoon fishery.

Comparison of ex-vessel price among the different swordfish fisheries operating within the CA EEZ suggests that DSBG product is received at a comparable price-point to that of the traditional California harpoon fishery (Coan et al., 1998; PFMC, 2013) and nearly twice the ex-vessel price of DGN-caught swordfish (PFMC, 2017; Fukushima ${ }^{4}$ ). Although DSBG swordfish was consistently received at a higher price point than DGN product, DGN operations do also provide other products that can significantly contribute to trip revenue (Hanan et al., 1993). Returns from opah, several tuna species, and pelagic sharks can, at times, make up a significant component of the DGN revenue, a factor that makes direct profitability comparisons between DSBG and DGN more complex than just comparing swordfish alone. Further, given that most of the DGN caught swordfish in this study were landed in the late fall and early winter, the timing of the landings also makes landing and profitability comparisons difficult to interpret.

In the cursory estimation of trip expenses, vessel financing costs were not considered, as all individuals participating in the EFP owned their vessels outright. Other factors that may have artificially inflated revenue estimates include the standardization of catch statistics, variability in the number of travel days, and any fish transport costs that may have been paid by the fisherman. Standardization of the fishing day length was necessary because of the occasional short soak period (1-3 h) of some sets in both study years, a factor that further complicated catch and effort comparisons with other gears and studies.

The scaling of the results from this study to a larger DSBG fleet are also difficult to interpret, as market demand and price resilience are affected by many factors including fleet size, import volume, and market strength or resilience (Urbisci et al., 2016). Future work should focus on market demand and how it relates to fleet size and profitability, factors that are needed for estimating optimal performance of any future fishery.

\section{Sensitive Species Interaction}

Although selective, DSBG trials had two observed interactions with northern elephant seals (one during the EFP and one during the research trials), a species that is abundant in the study area with a stock status that is not considered to be at risk (Lowry et al., 2014). The interactions confirmed the utility of the strike detection system in alerting fishermen to the presence of something on the line with both elephant seals (EFP and research vessel) being released promptly $(<15$ min) after the initial strike. Given the similar depth distribution and foraging behavior exhibited by swordfish and northern elephant seals it is unlikely that gear depth can be further altered to avoid future interactions (Le Boeuf et al., 1986; Maxwell et al., 2011). However, if deemed necessary, future work focused on northern elephant seal sensory biology may help identify possible methods to avoid future gear interactions. Similarly, ongoing work to develop electronic strike detection mechanisms may also reduce the amount of time non-targets spend on the line, a factor that has been shown to directly affect survivorship in many species (Gilman et al., 2006).

\section{Research Trials}

Experimental DSBG deployments were performed aboard the R/V $\mathrm{Ma}$ lolo to directly compare catch composition and selectivity between deep-daytime and shallow-nocturnal operations. Day and night sets were performed adjacent to ongoing EFP operations using similar set criterion (i.e., bathymetry, sea surface temperature, and productivity convergence). Nocturnal trials resulted in a catch that was largely dominated by elasmobranchs; with blue, mako, bigeye thresher, and smooth hammerhead sharks, Sphyrna zygaena, comprising $\sim 90 \%$ of the catch. Blue and mako sharks have been shown to use the $\mathrm{SCB}$ as a rookery, with large numbers 
of juveniles present during most of the swordfish fishing season (Tricas, 1979; Hanan et al., 1993; Sepulveda et al., 2004).

Similarly, both blue and mako sharks have been shown to display a mixed layer distribution at night with only the occasional excursion below the thermocline during the day (Holts and Bedford, 1990; Carey and Scharold, 1990; Sepulveda et al., 2004). Given that blue sharks were the most abundant (76.5\%) non-marketable species encountered in the nocturnal trials, two individuals were electronically tagged to confirm previous movement studies and evaluate if interaction rates could be reduced through modifying nocturnal set depth. When compared to previous swordfish movement data (Sepulveda et al., 2010 and 2014) as well as the two tracks from swordfish tagged during this study, it was evident that both species exhibit significant overlap in nocturnal depth distribution (Fig. 3). Overlapping depth distribution coupled with the blue shark's abundance in the SCB likely led to the high interaction rate observed during the night sets (Obrien and Sunada, 1994). These findings align with previous shallow-set longline experiments performed in the 1990's within the same study area which reported that $>90 \%$ of the catch was composed of both blue and mako sharks (Obrien and Sunada, 1994).

In addition to the high shark catch rates, bait predation was also a major factor contributing to the low swordfish catch at night. Shallow-set nocturnal deployments exhibited greater rates of bait predation (24\%) relative to deep-set daytime trials $(<5 \%)$, a result that supports the heightened competition for baited hooks in the upper mixed layer at night. During the nocturnal trials, it was assumed that juvenile blue sharks $(<100 \mathrm{~cm})$ were the primary source of bait predation. This was proposed due to characteristics of the bite marks, monofilament damage, and field observations of small blue sharks finning proximal to the deployment sites.

\section{Conclusion}

This work offers insight into the use of DSBG as a commercial fishing technique for harvesting west coast swordfish. Data support previous findings on DSBG off California and suggest high selectivity for swordfish and the live release of non-target catch. Given the decline in participation among California's west coast swordfish industry, this work provides a first step towards the development of sustainable techniques for harvesting a valuable domestic resource. Given that swordfish are capable of significant migrations and inter-annual changes in regional distribution, it is imperative that future work test the effectiveness of deep-setting throughout the range of the historic west coast fishery. Gear testing and exempted trials outside the SCB will help build a robust industry that can tolerate seasonal changes in abundance and further capitalize on this highly mobile domestic resource.

\section{Acknowledgments}

This material is based upon work supported by the NMFS SaltonstallKennedy Grant Program, the Bycatch Reduction and Engineering Program, The Pew Charitable Trusts, The Nature Conservancy, Santa Monica Seafood and the Fish Wise Program, the George T. Pfleger Foundation, the Offield Family Foundation, and the William H. and Mattie Wattis Harris Foundation. Tagging work was supported in part by the National Science Foundation under Grant Number IOS-1354772 and IOS-1354593. Any opinions, findings, and conclusions or recommendations expressed in this material are those of the author and do not necessarily reflect the views of the National Science Foundation. Special thanks are offered to Paul Tutunjian, Donald Krebs, Anthony Makul, Lance Rinehart, Bill Sutton, Johnny Foster, Kelly Fukushima, Andrew White, Chris Fanning, Christina Fahy, Corey Burwell, Corey Chan, Ralph Pace, Thomas Cowboy Fullam, Michael Wang, Craig Heberer, and Jennifer Thirkell. Lastly, we would like to ac- knowledge the support and hard work from management partners (Highly Migratory Species Management Team, Pacific Fisheries Management Council, California Department of Fish and Wildlife, and the NOAA NMFS West Coast Region).

\section{Literature Cited}

Bernal, D., C. A. Sepulveda, M. Musyl, and R. Brill. 2009. The eco-physiology of swimming and movement patterns of tunas, billfishes and large pelagic sharks. In P. Domenici and B. G. Kapoor (Editors), Fish locomotion: An eco-ethological approach, p. 436-483. Sci. Publ., Einfeld

Beverly, S., and E. Robinson. 2004. New deep setting longline technique for bycatch mitigation. AFMA Final Res. Rep. R03/1398. Secretariat of the Pacific Community, Noumea, 30 p. (Online at http://www.spc.int/DigitalLibrary/Doc/FAME/Reports/Beverly_04_Bycatch.pdf).

Bograd, S. J., C. G. Castro, E. Di Lorenzo, D. M. Palacios, H. Bailey, W. Gilly, and F. P. Chavez. 2008. Oxygen declines and the shoaling of the hypoxic boundary in the California Current. Geophys. Res. Lett. 35, L12607. (doi: https://doi.org/10.1029/2008GL034185).

Carey, F. G. 1990. Further observations on the biology of the swordfish. In R. H. Stroud (Editor), Planning the future of billfishes, $\mathrm{p}$. 103-122. Natl. Coalition Mar. Conserv., Savannah, Ga.

and B. H. Robison. 1981. Daily patterns in the activities of swordfish, Xiphias gladius, observed by acoustic telemetry. Fish. Bull. 79:277-292.

and J. V. Scharold. 1990. Movements of blue sharks Prionace glauca, in depth and course. Mar. Biol. 106:329-342. (doi: https://doi.org/10.1007/BF01344309).

Carretta, J. V., T. Price, D. Petersen, and R. Read. 2004. Estimates of marine mammal, sea turtle, and seabird mortality in the California drift gillnet fishery for swordfish and thresher shark, 1996-2002. Mar. Fish. Rev. 66(2):21-30

Coan, A. L., M. Vojkovich, and D. Prescott. 1998. The California harpoon fishery for swordfish, Xiphias gladius. In I. O. Barrett, Sosa-Nishizaki, and N. Bartoo (Editor), Biology and Fisheries of Swordfish, Xiphias gladius. Papers from the International Symposium on Pacific Swordfish, Ensenada, Mexico, 11-14 December 1994, p. 37-49. U.S. Dep. Commer., NOAA Tech. Rep. NMFS 142.

Dailey, M. D., D. J. Reish, and J. W. Anderson. 1993. Ecology of the Southern California Bight: A synthesis and interpretation. Univ. Calif. Press, p. 2-3.

Dewar, H., E. D. Prince, M. K. Musyl, R. W. Brill, C. A. Sepulveda, J. Luo, D. Foley, E S. Orbesen, M. L. Domeier, N. Nasby-Lucas, D. Snodgrass, R. M. Laurs, J. P. Hoolihan, B. A. Block, and L. M. McNaughton. 2011. Movements and behaviors of swordfish in the Atlantic and Pacific Oceans examined using pop-up satellite archival tags. Fish. Oceanogr. 20(3):219-241. (doi: https://doi. org/10.1111/j.1365-2419.2011.00581.x).

Eguchi, T., S. Benson, D. Foley, and K. A. Forney. 2016. Predicting overlap between drift 
gillnet fishing and leatherback turtle habitat in the California Current Ecosystem. Fish Oceanogr. 26:17-33. (doi: https://doi.org/10. 1111 /fog.12181)

Gilman, E., E. Zollett, S. Beverly, H. Nakano, K. Davis, D. Shiode, P. Dalzell, and I. Kinan. 2006. Reducing sea turtle by-catch in pelagic longline fisheries. Fish Fish. 7(1):2-23.(doi:https://doi.org/10.1111/j.14672979.2006.00196.x)

D. Kobayashi, T. Swenarton, N. Brothers, P. Dalzell, and I. Kinan-Kelly. 2007. Reducing sea turtle interactions in the Hawaii-based longline swordfish fishery. Biol. Conserv. 139:19-28. (doi: https://doi. org/10.1016/j.biocon.2007.06.002)

Hanan, D. A., D. B. Holts, and A. L. Coan, Jr. 1993. The California drift gill net fishery for sharks and swordfish, 1981-82 through 1990-1991. Calif. Dep. Fish Game Bull. 175, 95 p. (Online at https://swfsc.noaa.gov/publications/CR/1993/9342.PDF).

Holts, D. B., and D. W. Bedford. 1990. Activity patterns of striped marlin in the Southern California Bight. In R. Stroud. (Editor), Planning the future of billfishes: research and management in the 90's and beyond, $\mathrm{p}$. 81-93. Natl. Coalition Mar. Conserv. Atlanta, Ga. (Online at https://swfsc.noaa.gov/publications/CR/1990/9024.PDF).

Kerstetter, D., and S. Bayse. 2009. Characterization of the catch by swordfish buoy gear in southeast Florida. CRP Contract No. NA07NMF4540075, 25 p. (Online at https:// grunt.sefsc.noaa.gov/P_QryLDS/download/CR929_CRP\%20Report_\%20NA07NMF4540075.pdf?id=LDS).

Le Boeuf, B. J., D. P. Costa, A. C. Huntley, G. L. Kooyman, and R. W. Davis. 1986. Pattern and depth of dives in northern elephant seals, Mirounga angustirostris. J. Zool., Lond. 208:1-7.

Levin, L. A. 2003. Oxygen minimum zone benthos: adaptation and community response to hypoxia. Oceanogr. Mar. Biol. Annu. Rev. 41:1-45.

Lowry, M.S., R. Condit, B.Hatfield, S.G. Allen, R. Berger, P.A. Morris, B.J. Le Boeuf, and J. Reiter. 2014. Abundance, distribution, and population growth of the northern elephant seal (Mirounga angustirostris) in the United States from 1991 to 2010. Aquatic Mammals 40(1):20-31. (doi: https://doi.org/ 10.1578/ AM.40.1.2014.20)

Martin, S. L., S. M. Stohs, and Moore, J. E. 2015. Bayesian inference and assessment for rare-event bycatch in marine fisheries: a drift gillnet fishery case study. Ecol. Appl. 25:416-429

Maxwell, S. M., J. J. Frank, G. A. Breed, P. W. Robinson, S. E. Simmons, D. E. Crocker, J.
P. Gallo-Reynoso, and D. P. Costa. 2011 Benthic foraging on seamounts: a specialized foraging behavior in a deep-diving pinniped. Mar. Mammal. Sci. 28(3):E333E344. (doi: https://doi.org/10.1111/j.1748-7 692.2011.00527.x)

Nakano, H., M., Okazaki, and H. Okamoto. 1997. Analysis of catch depth by species for tuna longline fishery based on catch by branch lines. Bull. Nat. Res. Inst. Far Seas Fish. 34:43-62.

NOAA. 2001. Endangered and threatened wildlife; sea turtle conservation requirements; taking of threatened or endangered species incidental commercial fishing operations. Fed. Regist. 66 FR 44549: 44,549-44,552. (Online at https://www.gpo.gov/fdsys/pkg/ FR-2001-08-24/pdf/01-21512.pdf).

2014. Fisheries off west coast

states; highly migratory fisheries; California drift gillnet fishery; sperm whale interaction restrictions. Fed. Regist. 79 FR 29377: 29,377-29,379. (Online at https://www.gpo. gov/fdsys/pkg/FR-2014-05-22/pdf/201411658.pdf)

Obrien, J. W., and J. S. Sunada. 1994. A review of the southern California experimental drift longline fishery for sharks, 1988-1991. CalCOFI Rep. 35:222-229.

Pacific Fishery Management Council (PFMC). 2013. Status of the U.S. west coast fisheries for highly migratory species through 2012: Stock assessment and fishery evaluation, 70 p. (Online at http://www.pcouncil.org/wpcontent/uploads/HMS_SAFE_2013_FINAL. pdf).

2017. Status of the U.S. west coast fisheries for highly migratory species through 2015: Stock assessment and fishery evaluation. Pac. Fish. Manag. Counc., 76 p. (Online at http://www.pcouncil.org/wp-content/ uploads/2017/01/2016-HMS-SAFE-Reportarchive-copy.pdf).

Palacios, D. M., S. J. Bograd, R. Mendelssohn, and F. B. Schwing. 2004. Long-term and seasonal trends in stratification in the California Current, 1950-1993. J. Geophys. Res.109:C10016. (doi: https://doi. org/10.1029/2004JC002380).

Prince, E. D., and C. P. Goodyear. 2006 Hypoxia-based habitat compression of tropical pelagic fishes. Fish. Oceanogr. 15:451-464. (doi: https://doi.org/10.1111/ j.1365-2419.2005.00393.x).

Rausser, G., S. Hamilton, M. Kovach, and R. Stifter. 2009. Unintended consequences: the spillover effects of common property regulations. Mar. Pol. 33(1):24-39. (doi: https://doi. org/10.1016/j.marpol.2008.03.020).

Sepulveda, C. A., S. Kohin, C. Chan, R. Vetter, and J. B. Graham. 2004. Movement patterns, depth preferences, and stomach temperatures of free-swimming juvenile mako sharks, Isurus oxyrinchus, in the Southern California Bight. Mar. Biol. 145:191-199. (doi: https:// doi.org/10.1007/s00227-004-1356-0).

A. Knight, N. Nasby-Lucas, and M. L. Domeier. 2010. Fine-scale movements and temperature preferences of swordfish in the Southern California Bight. Fish. Oceanogr. 19(4):279-289. (doi: https://doi. org/10.1111/j.1365-2419.2010.00543.x). C. Heberer, and S. A. Aalbers. 2014. Development and trial of deep-set buoy gear for swordfish, Xiphias gladius, in the Southern California Bight. Mar. Fish Rev. 76:28-36. (doi: https://doi.org/10.7755/ MFR.76.4.2)

S. A. Aalbers, C. Heberer, S. Ko-

hin, and $H$. Dewar. 2018. Movements and behaviors of swordfish Xiphias gladius in the United States Pacific Leatherback Conservation Area. Fish Oceanogr. 27:381-394. (doi: https://doi.org/10.1111/fog.12261)

Tricas, T. C. 1979. Relationships of the blue shark, Prionace glauca, and its prey species near Santa Catalina Island, California. Fish. Bull. 77(1):175-182.

Uchiyama, J. H., E. E. DeMartini, and H. A. Williams. 1999. Length-weight interrelationships for swordfish, Xiphias gladius L., caught in the central North Pacific. U.S. Dep. Commer., NOAA Tech. Memo. NMFS-SWFSC-284, $82 \mathrm{p}$.

Urbisci, L. C., S. Stohs, and K. Piner. 2016. From sunrise to sunset in the California Drift Gillnet fishery: an examination of the effects of time and area closures on the catch and catch rates of pelagic species. Mar. Fish. Rev. 78(3-4):1-11. (doi: https://doi.org/10.7755/ MFR.78.3-4.1)

Ward, P., J. M. Porter, and S. Elscot. 2000. Broadbill swordfish: status of established fisheries and lessons for developing fisheries. Fish Fish. 1:317-336. (doi: https://doi org/10.1046/j.1467-2979.2000.00026.x).

Weng, K. C., and B. A. Block. 2004. Diel vertical migration of the bigeye thresher shark (Alopias superciliosus), a species possessing orbital retia mirabilia. Fish. Bull. 102:221-229.

Western and Central Pacific Fisheries Commission (WCPFC). 2014. North Pacific swordfish (Xiphiaus gladius) stock assessment in 2014. International Scientific Committee for Tuna and Tuna-like Species in the North Pacific Ocean, Billfish Working Group Pape WCPFC-SC10-2014/ SA-WP-13. (Online at https://www.wcpfc.int/system/files/SC10 SA-WP- $13 \% 20$ North $\% 20$ Pacific\%20Swordfish $\% 20$ Assmt $\% 20$ Report $\% 202014$.pdf). 